\title{
Bibliometric Overview on Energy-Water Nexus Research in the Chinese Literature
}

\author{
Jingli Fan ${ }^{1,2}$, Bing Wang ${ }^{1}$, Qinying Song ${ }^{1}$, Fengyu Li $^{3,4}$ and Xian Zhang ${ }^{5 *}$ \\ ${ }^{1}$ College of Resources and Safety Engineering, China University of Mining and Technology (Beijing), Beijing, China \\ ${ }^{2}$ State Key Laboratory of Coal Resources and Safe Mining (China University of Mining and Technology), Beijing, China \\ ${ }^{3}$ School of Finance, Central University of Finance and Economics, 100081 Beijing, China \\ ${ }^{4}$ TIAS School for Business and Society, Tilburg University, 5000 LE Tilburg, Netherlands. \\ ${ }^{5}$ The Administrative Centre for China's Agenda 21, Ministry of Science and Technology, Beijing, China
}

\begin{abstract}
With the background of water shortages and serious water pollution, issues of water involved in energy exploration and utilization have become critical problems affecting urban water usage. In order to identify the relationships of the energywater nexus, this paper characterizes the energy-water nexus literature using a bibliometric method and based on the Chinese National Knowledge Infrastructure database platform. The results reveal that 1) Scientific outcomes in this field have increased sharply since 2003, with a slightly higher growth rate than that of general disciplines. 2) China Water Resources, Yangtze River and Express Water Resources \& Hydropower Information are the dominant journals, and the main research fields include industrial economics, environmental science, and management, among other disciplines. 3) Hohai University, the Chinese Hydraulic Engineering Society, the Institute of Geographic Sciences and Natural Resources Research, and the Changjiang Water Resources Commission are the main research institutions in this field. However, the proportion of publications of these institutions is not high, which suggests that there is no institution dominating this field. 4) According to the keyword analysis, the hot spots in this field include ecological environment, sustainable development, environmental protection, climate change, etc. Energy-mining related keywords have increased over time, implying that the energy-water nexus from the perspective of the energy exploitation industry can become a key issue. At the same time, the frequency of keywords related to sustainable development has been maintained at a high level, and the studies concerned with the impacts of climate change were introduced into this field relatively late. The conclusion of this study provides a foundation for a comprehensive understanding of the current situation as well as for further research in the energy-water nexus field.
\end{abstract}

Keywords: water resources, energy, energy-water nexus, impact, climate change

\section{Introduction}

As an important strategic resource for national economic and social sustainable development, water has been increasingly focused on by the Chinese Government. Over the next decade, the total water demand of China will continue to grow steadily, which lead to a significant trend of increasing water consumption in the future (Zhang 2013). To reasonably exploit, utilize, conserve and protect water resources, the Water Law of the People's Republic of China was enacted by the members of the 9th National People's Congress Standing Committee in 1988 and after multiple revisions, the latest of which, in September 1, 2016, has involved water infrastructures in the national economic and social development plans of the government at all levels and regulated the rationale for water engineering construction. Thus, in the context of serious water shortages and water pollution, China's government has taken several measures to make rational use of water resources.

Due to the serious water shortages and water pollution, water utilization issues of energy systems are increasingly troubling to society. First of all, in energy exploitation and electricity generation, water is an indispensable resource. At the same time, in a country with a coal-dominated energy structure and a thermal \& hydro-dominated power structure, China's energy system and power system are highly water-dependent. Further, agriculture accounts for the largest proportion of the total water usage of society, creating a conflict with energy systems using water. Thus, it is necessary to promote efficient water-saving in power sectors and water-saving irrigation in the agricultural sector. Furthermore, Chinese citizens' awareness of water saving is relatively low, so energy saving and water conservation can be promoted collaboratively.

IEA (2012) confirmed that water issues could affect the availability of energy and costs of energy utilization, with water restrictions on energy extended in future. Studies from the Department of Energy have shown, that, essential factors in energy production and power generation, water production, transmission, distribution, as well as wastewater treatment and recycling, consume a large amount of energy; the reciprocal relationship between energy and water constitutes an important feature of the "energy-water nexus", and climate change has made the bi-

* Corresponding Author: X. Zhang, email: zx_ama@hotmail.com, phone: +86 10-58884888

Copyright (C 2017 Canamaple Academia Services, http://press.camdemia.ca

DOI: 10.15273/gree.2017.02.029 
directional links between them stronger. Chinese scholars have also developed several studies concerning the energywater nexus (US Department of Energy 2014). Bao et al (2015) combed international dynamics regarding the energy-water nexus, providing significant ideas for China's coordinated development of water resources and energy. $\mathrm{Hu}$ and $\mathrm{Xu}$ (2015), from the perspective of policies and laws, combined with the experience and lessons of American energy-water nexus legislation, concluded that establishing coordination mechanisms between energy and water resource management would have a huge positive impact on the realization of synergies between energy and water management. Hence, research on the energy-water nexus can become a key factor in energy policy research in the future.

Bibliometric methods can effectively describe the development of the law of various disciplines, having been widely applied to climate policy, climate change risk assessment. Zhang (2016), using bibliometric and review methods, studied the latest progress and main directions of the development of carbon tax, as well as summing up the main points of carbon tax. Chang and Hsieh (2008) using bibliometric methods, systematically arranged the development trends of Asian management science and operations research, as well as discussing its development trends and hot spots from 1968 to 2006.

To measure the current situation of energy-water nexus researches, this study is based on publications of energy-water nexus searched for in the Chinese National Knowledge Infrastructure (CNKI) database, utilizing reverse multiple retrieval method to search literature, and choosing bibliometrics as the method to analyze the publications in this field in order to quantify the development of the discipline as well as the research development trends and salient questions in the field.

\section{Methodology}

This study uses the CNKI database as, with the energywater nexus as the main keyword. Five indicators of literature analysis and discussion about energy-water nexus were identified through the use of the reverse thinking method in searching and retrieving literature, including quantitative analysis literature, source analysis literature, subject distribution, main research institutions and keyword hotspot analysis. The first page has a fixed header and footer, as shown on this page and we needed only to fill in the appropriate information in the footer: corresponding author's name, e-mail address and phone number. The reverse multiple database retrieval process used in this study is as follows (as shown in Figure 1). First stage: group discussions to establish the query for the first time. We first adopted the form of an experts' group discussion to identify the first query as $\mathrm{SU}=$ (water resource $*$ (energy + electricity + oil + petroleum + coal + gas) * (influence + impact)). We collected 3089 studies from January 1, 1979 to September 1, 2016, comprising journal articles, conference papers, degree dissertations and newspaper articles.
Second stage: separating the synonymous key words. We used bibliometric analysis software Bibexcel to analyze all keywords. Having examined and arranged all the literature, we found various synonyms of different field tags in the energy-water nexus literature.

Third stage: redefining query. According to the arrangement of the second stage, we redefined the query as $\mathrm{SU}=((($ water resource + water demand + water consumption + water shortage + water utilization + water pollution + water treatment + water damage + sewage disposal + water-saving techniques $) *($ energy + fuel + petroleum + gas + electricity + thermal power + hydroelectric generation + nuclear power + wind power + solar energy + coal + coal electricity + power generation + energy exploitation + water-saving techniques) * (influence + impact + relationship + correlation) $)+$ (energy-water nexus + water-energy nexus + energy-water relationship + water-energy relationship)). Holding the other conditions as before, 6933 publications were retrieved.

Fourth stage: arranging and analyzing the literature. Having arranged the retrieval literatures from the perspective of author, institution and synonyms (seeing arrangement strategy in Figure 1), we came to 3219 literatures and analyzed them by bibliometric analysis methods.

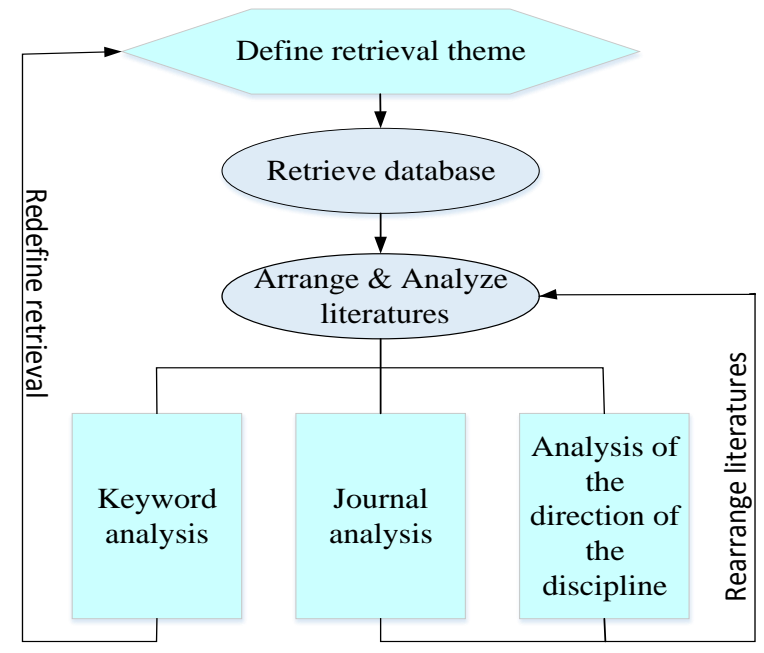

Figure 1. The reverse multiple retrieval method.

Based on the strategy shown in Figure 1, we sorted, refined and adjusted the literatures. In the third stage, we first we complemented and refined the retrieval phases according to keywords and determined final keywords. As to the name of journal source, because early journals in the database might have changed their names, we searched the web page to make a comparison with original text or classify journals to solve this problem and arrange the literature. Having found large numbers of dissertation and journal papers written by the same authors, we limited the search scope to journal papers, omitting dissertations. Next, addressing the issue of which discipline a study belonged to, we grouped the apparent engineering or technology researches in the technical disciplines field. 
Finally, through browsing all the literature artificially, we deleted 5 studies that clearly did not belong to energy-water nexus field. There were, thus, a total of 3,214 studies used for bibliometric analysis. This paper applied the Price index to analyze whether the growth of literature followed the exponential growth law.

\section{Results and Discussion}

Based on the data above, we used bibliometric methods to analyze systematically the research trends of energy-water nexus, including the increasing situation of publications, the distribution of literatures disciplines and publication types, sources, major research institutions, and keyword frequency analysis.

\subsection{The analysis of literatures amounts}

The growth of academic literature is one of the most important measures of the research development of the discipline. As statistics show, scholars of energy-water nexus issues published 3012 studies in total from 1979 to 2015 (without a further 202 studies published from January to September in 2016) and the total number of publications per year rose from 4 in 1979 to 336 in 2015 . The total number of publications per year from 1979 to 2016 is shown in Figure 2.

From Figure 2, it can be seen that the increase in the number of publications on the energy-water nexus, as a new research interest, fluctuated from 1979 to 2002. Since 2003, the number of has grown rapidly, demonstrating a rapid development trend in energy-water nexus research and considerable attention to this field paid by scholars who study energy externalities. Bibliometric research shows that the growth in the literature corresponds closely to exponential growth laws. Price set the number of scientific studies as the longitudinal axis and the historical periods as the horizontal axis; thus the process of change in publications in different years can be represented as a smoothing curve which approximately expresses the exponential growth law in the volume of scientific literature. So we can conclude from Price's research that the amount of literature from any normal and increasing discipline grows exponentially, increasing approximately once every 10 to 15 years, about 5\%-7\% per year (Jing and Kang 2000)

Figure 2 also shows the cumulative growth of the energy-water nexus literature. According to the development rate, this can be roughly divided into 3 stages: 1979-1986 was the initial stage; between 1987 and 2002, it entered a stage of fluctuating development, and; 2003-2015 was the stage of rapid development. Because 1979-2002 is the preliminary phase of literature on the energy-water nexus, we fit the laws of literature growth from 2003 and obtained the estimated equation of energy-water nexus researches from 2003 to $2015, \mathrm{~F}(\mathrm{t})=711 e^{0.119 t}\left(R^{2}=\right.$ $0.999)$, which shows that the growth rate of energy-water nexus literature was faster than that of literature on general disciplines.

\subsection{Disciplines distribution analysis}

According to the CNKI database retrieval results, the studies on the energy-water nexus are distributed among 65 discipline categories.

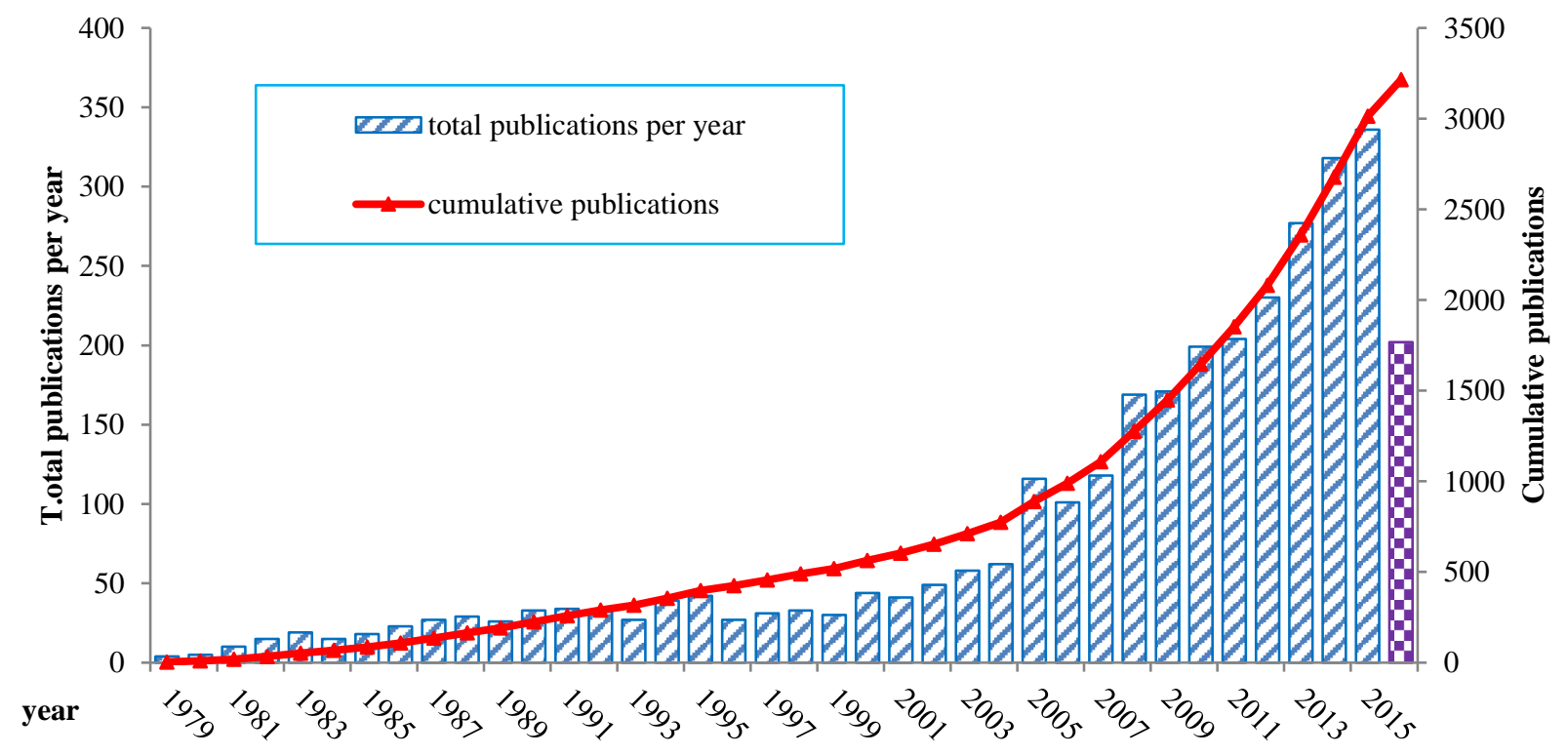

Figure 2. The development trend of energy-water nexus researches from 1979 to 2016. 


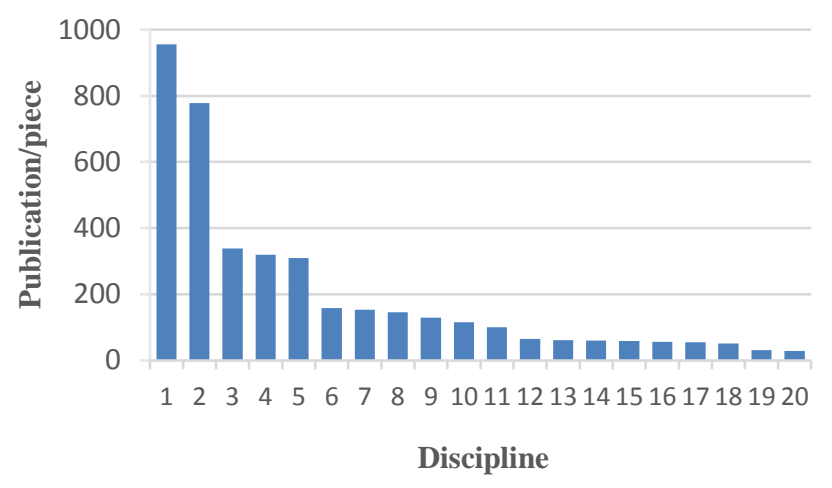

Figure 3. The disciplines distribution of energy-water nexus research. Note:

1 Hydraulic and Hydro-Power Engineering

2 Environmental Science and Resource Utilization

3 Industrial Economy

4 Electrical Industry

5 Resources Science

6 Mining Engineering

7 Macroeconomic Management and Sustainable Development

8 Architectural Sciences and Engineering

9 Oil and Gas Industry

10 Economic Structural Reform

11 Geology

12 Geophysics

13 Organic Chemical Industry

14 Inorganic Chemical Industry

15 Dynamical Engineering

16 Agricultural Economics

17 Meteorology

18 Agricultural Engineering

19 Light \& Handicraft Industry

20 Agricultural Basic Science

As shown in Figure 3, there are more than 150 journal articles on hydraulic and hydro-power engineering, environmental sciences and resources utilization, industrial economy, electrical industry, resources science, mining engineering, macroeconomic management and sustainable development $i$ in this field, with 955, 778, 338, 320, 309, 159 and 153 publications respectively. In this light, we can confirm that the research themes of the energy-water nexus not only contain resources, mining, electricity, water conservancy, but reflect the importance of the disciplines of industrial economy, environmental science, management and economics in the study of energy-water nexus. Involving two aspects of energy and water, the distributions of disciplines in energy-water nexus research suggest that there are more studies on the perspective of water. At the same time, from the viewpoint of time, studies on the environment, energy, economic and management are increasing.

\subsection{Journal analysis}

The analysis of literature is supposed to focus on the sources and this paper focuses on the source journals. Table 1 shows the distribution of the top 10 productive journals, representing about $10.92 \%$ of the publications. China Water Resources was the most productive journal with 56 publications, followed by Yangtze River with 49 publications, then Express Water Resources and Hydropower Information with 45 publications each, which shows that Chinese energy-water nexus studies were published in different journals, reflecting the multidisciplinary characteristic of cross subjects.

Table 1. Journals with research on the energy-water nexus.

\begin{tabular}{clc}
\hline No. & \multicolumn{1}{c}{ Journal } & Publication No. \\
\hline 1 & China Water Resources & 56 \\
2 & Yangtze River & 49 \\
3 & Express Water Resources \& Hydropower & 45 \\
& Information & 37 \\
4 & Heilongjiang Science and Technology & \\
& Information & 32 \\
5 & Journal of Hydraulic Engineering & 24 \\
6 & Ground Water & 24 \\
7 & China Population, Resources and & 22 \\
& Environment & 22 \\
8 & Industrial Water Treatment & 20 \\
9 & Yellow River & Chemical Enterprise Management \\
10 & ZHIHUAI & 20 \\
\hline
\end{tabular}

\subsection{Analysis of main institutions}

The 3214 publications retrieved for energy-water nexus analysis in this study were sourced from more than 60 different research institutions. The top 10 productive institutions are shown in Table 2. Hohai University was the most productive institution, with 37 publications representing $1.15 \%$ of the total, followed by the Chinese Hydraulic Engineering Society with 33 publications, representing $1.03 \%$. The top research institutions also included the Institute of Geographic Science and Resources Institute, and the Yangtze River Water Resources Commission, Tsinghua University, among others. Having analyzed these institutions, we can see that the proportion of publications of the highly productive institutions is not very high and no single institution was dominant in terms of energy-water nexus research.

\subsection{Keywords analysis}

Exploring the current hot spots is the key to understanding the development law of a discipline. With the development of a discipline, the researchers in this field will focus on certain research directions or go in different research directions, thus producing the research hot spots or the latest progress. Keyword analysis is the main method of understanding research themes and points in a field.

Based on the final query, we arranged keyword distribution of energy-water nexus research, as shown in table 3. In terms of keyword frequency, phrases related to water resources in the query appeared 309 times in the retrieved studies and those related to hydraulic 
Table 2. The research institutions of the energy-water nexus literature.

\begin{tabular}{|c|c|c|}
\hline No. & Institution & Pub. No. \\
\hline 1 & Hohai University & 37 \\
\hline 2 & Chinese Hydraulic Engineering Society & 33 \\
\hline 3 & $\begin{array}{l}\text { Institute of Geographic Sciences and } \\
\text { Natural Resources Research }\end{array}$ & 32 \\
\hline 4 & $\begin{array}{l}\text { Changjiang Water Resources } \\
\text { Commission }\end{array}$ & 30 \\
\hline 5 & Tsinghua University & 25 \\
\hline 6 & $\begin{array}{l}\text { China University of Mining and } \\
\text { Technology }\end{array}$ & 24 \\
\hline 7 & Sichuan University & 22 \\
\hline 8 & $\begin{array}{l}\text { China Institute of Water Resources and } \\
\text { Hydropower Research }\end{array}$ & 21 \\
\hline 9 & $\begin{array}{l}\text { University of Chinese Academy of } \\
\text { Sciences }\end{array}$ & 21 \\
\hline 10 & Xi'an University of Technology & 20 \\
\hline 11 & Wuhan University & 18 \\
\hline 12 & Peking University & 15 \\
\hline 13 & Beijing Normal University & 15 \\
\hline 14 & North China Electric Power University & 15 \\
\hline 15 & $\begin{array}{l}\text { China University of Mining and } \\
\text { Technology(Beijing) }\end{array}$ & 13 \\
\hline 15 & Nanjing Hydraulic Research Institute & 13 \\
\hline 15 & $\begin{array}{l}\text { Research Center for Eco-Environmental } \\
\text { Sciences, Chinese Academy of Sciences }\end{array}$ & 13 \\
\hline 18 & Nanjing University & 12 \\
\hline 19 & Tongji University & 11 \\
\hline 20 & Tianjin University & 11 \\
\hline 20 & Shaanxi Normal University & 11 \\
\hline 20 & Chang'an University & 11 \\
\hline
\end{tabular}

engineering science appeared 116 times. Thus, we can see that hydraulic engineering science was the most frequently occurring keyword except for the phrases from the query, and it has a great relevance to energy-water nexus research. Furthermore, in the non-retrieval phrases, ecological environment, sustainable development, environmental protection and climate change were believed to be the research themes which had the closest relations with energy-water nexus research. Keyword analysis further showed that the energy-water nexus research is an interdisciplinary field involving hydrology, energy engineering, environmental science and climatology. In particular, the emergence of climate change as a keyword shows that research on China's energy-water nexus has taken it into account over time.

\subsection{The analysis of keyword frequency}

In the analysis of keywords, we summarized the overall frequency statistics of keywords retrieved in the whole period of time and found the main concerns of this field over the years. However, this analysis of keywords frequency in the time frame could not capture hot spot shifting trends over time. Based on this, we range the literatures according to published year and choose every 200 academic papers as a threshold to specific analysis for the distribution characteristics of keyword. Results are shown in Figure 4.

Table 3. The keyword distribution of energy-water nexus research.

\begin{tabular}{llll}
\hline No. & Category name & Keywords & Frequency \\
\hline 1 & Water resource related & Water resource related & 309 \\
\hline \multirow{2}{*}{2} & \multirow{2}{*}{ Hydraulic engineering category } & Hydraulic engineering & 47 \\
\cline { 3 - 4 } & & Hydraulic \& hydro-power engineering. & 43 \\
\cline { 3 - 4 } 3 & \multirow{2}{*}{ Effect category } & Hydraulic and hydro-power & 26 \\
\cline { 3 - 4 } & Water treatment & Environmental effects & 55 \\
\hline 4 & \multirow{2}{*}{5} & Water treatment & 44 \\
\hline \multirow{2}{*}{6} & Strategies and measures category & Eco-environment & 81 \\
\cline { 3 - 4 } & & Environment & 52 \\
\hline 7 & Coal mining & Strategies & 29 \\
\cline { 3 - 4 } & Measures & 49 \\
\hline 9 & Sustainable development & Coal mining & 26 \\
\hline 10 & Climate change & Sustainable development & 70 \\
\hline 10 & Groundwater & Environmental protection & 62 \\
\hline
\end{tabular}




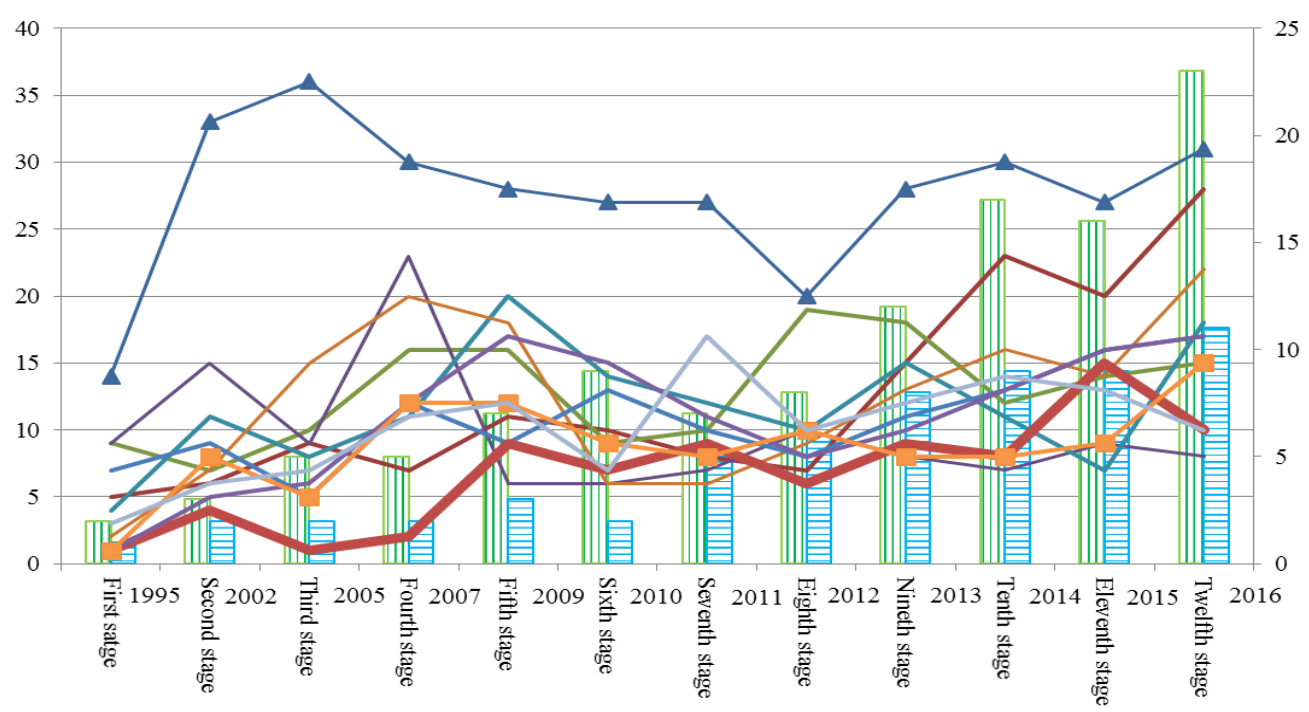

ㅍIII) resource exploitation

œclimate change

- -water resource

-hydraulics and hydropower related water pollution

-region

the social economy benefit

- the enervironment

-development and adjustment

water and energy conservation Strategies \& measures

- -sustainable development -infulence of affect

Figure 4. The frequency analysis of keywords in different periods.

It was found that energy-production category keywords including the coal mining category (coal mining \& exploitation) and the mining of shale gas occur with increasing frequently over time; therefore, the energy-water relationship in energy mining became the hot spot. What is noticeable is that the mining of shale gas appeared for the first time in 2013; in 2015 it occurred 13 times, and 8 times in 2016. Thus it can be seen that energy-water problems in shale gas production have caught the attention of researchers in the discipline.

The keyword distributions of sustainable development reveals that its mean value of frequency has been = maintained gradually at a higher level since 2005, which could be closely related to the "Scientific Development Concept" proposed in 2003. At the same time, the frequency of keywords on climate change has increased markedly since 2011, which implies that the impact of climate change on the energy-water nexus in China has just begun, and further studies are needed in the future. The frequency of keywords over time shows that:

(1) Water conservancy and hydrology are the basic characteristics of energy-water nexus researches as the related frequency of phrases of water resource, water conservancy and hydrology are on the top.

(2) 2012-2015, building suddenly appeared in the main keywords and the energy-water nexus research on building science characteristics should be explored.

(3) The research on the energy-water nexus shows the characteristics of local conditions. Keywords reflecting the feature of sectors and regions were always ranked in the forward position.

(4) The frequency of social economic keywords, including "efficiency, optimized allocation and recycling economy", is high.

\section{Main Conclusions}

Water and energy resources are the basis of the national economic development of China, but also of the essential factors in achieving social development (Wei et al 2015). The energy-water nexus is a research field based on the new trend of energy and water resource cooperative management to adapt to such new circumstances. This paper retrieved Chinese energy-water nexus literature from 1979 to 2016 based on the CNKI database and analyzed the development characteristics and trends using bibliometric methods. The main conclusions are as follows:

(1) The output of Chinese scientific research on the energy-water nexus is increasing. Since 2003, publications on energy-water nexus have increased dramatically and the growth rate of scientific research in this field was slightly higher than that of general disciplines. In addition, China Water Resources, Yangtze River, Express Water Resources and Hydropower Information are the dominant journals, indicating that this field is strongly associated with hydrology and water conservancy research.

(2) Analysis of the distribution of disciplines showed that the research themes of the energy-water nexus contained studies on resources, mining, electricity, water conservancy, as well as on industrial economy, environmental science, management science, economics, all of which are important aspects of the study in this field. The distribution of disciplines also reveals that there are currently more studies in this area from the perspective of water than energy; at the same time, environment, energy, economic and management aspects are increasingly taken into account.

(3) Keyword analysis showed that the integrated application of environmental management, economics, and engineering are the disciplines most characteristic of energywater nexus research. Furthermore, Hohai University, the Chinese Hydraulic Engineering Society, the Institute of Geographic Sciences and Natural Resources Research, the 
Changjiang Water Resources Commission, and Tsinghua University are the main research institutions in this field, revealing a high interrelation to the disciplines of engineering and mining.

However, as a relatively new research theme, current bibliometric analysis suggests that the distribution of literature is scattered and there are no clearly dominant mainstream journals or representative high-yield authors. Therefore, energy-water nexus research will continue. Finally, this study is based only on the CNKI database and it is necessary to combine this with literature in other languages for further analysis.

\section{Acknowledgement}

The authors gratefully acknowledge the financial support of the National Natural Science Foundation of China under Grant (no. 71503249), Beijing Excellent Talent Program (no. 2015000020124G122), the Open Research Project of State Key Laboratory of Coal Resources and Safe Mining (China University of Mining and Technology) (no. SKLCRSM16KFC05).

\section{References}

Bao, S.J., Y.W. Jia, X.R. Gao and S.Y. Cai, 2015. Trend and inspiration of water and energy nexus. China Water Resources, (11): 6 - 9. (in Chinese)

Chang, P.L. and P.N. Hsieh, 2008. Bibliometric overview of operations research/management science research in
Asia. Operations Research \& Management Science, 25(2): $217-241$.

$\mathrm{Hu}$, D.S. and S.Q. Xu, 2015. On energy-water nexus and perfection of China's energy and water policy and law. Journal of Xi'an Jiaotong University (Social Sciences), 35(4): 115 - 119. (in Chinese)

IEA (International Energy Agency), 2012. World Energy Outlook 2012. Paris, IEA.

Jing, P.D. and Z.Y. Kang, 2000. On the mathematical models of the growth of scientific literature. Journal of the China Society for Scientific and Technical Information, 19(1): 90 - 96. (in Chinese)

US Department of Energy, 2014. The water-energy nexus: challenges and opportunities. http://www.energy.gov/under-secretary-science-andenergy/downloads/water-energy-nexus-challenges-andopportunities 2014.

Wei, Y.M., Z.F. Mi and Z. Huang, 2015. Climate policy modeling: an online SCI-E and SSCI based literature review. Omega-The International Journal of Management Science, 57: 70 - 84.

Zhang, K., Q. Wang and Q.M. Liang, 2016. A bibliometric analysis of research on carbon tax from 1989 to 2014. Renewable \& Sustainable Energy Reviews, 58: 297 310 .

Zhang, L., 2013. China's water demand outlook for the next decade. Development Research, (11): 12 - 18. (in Chinese) 